\title{
Analisa Desain, Konsep, dan Karakteristik Sistem Transfer Daya Nirkabel
}

\author{
Ike Yuni Wulandari
}

Fakultas Teknik, Universitas Nurtanio, Bandung

*Koresponden email: ikeyunipp@gmail.com

Diterima: 1 Januari 2020

Disetujui: 11 Maret 2020

\begin{abstract}
In the current era of the industrial revolution 4.0, the need for time, labor, and cost efficiency is a basic requirement for human life, especially regarding electrical energy sources. The supply of commercial electricity is still using electricity cables to deliver electricity to the load. Therefore, one of the ways of sending or transferring electrical power that continues to be developed today is wireless electricity transfer. The wireless transfer of electric power has several advantages compared to the use of cables, which can increase the convenience in the use of electrical equipment and can reduce the amount of electronic waste. This research will study the techniques or methods of near-field wireless energy transfer systems, namely the inductive coupling method, the magnetic resonance coupling method and the capacitive coupling method. The results of this study propose an optimal modeling of wireless power transfer so that results and quality are better, taking into account the distance between the sender and receiver because the work efficiency of wireless power transfer decreases with respect to distance. And the signal transmission frequency is low for inductive coupling, while the resulting frequency will be high on magnetic resonance coupling and capacitive coupling.
\end{abstract}

Keywords: wireless power transfer, capacitive coupling, magnetic resonance coupling, inductive coupling

\begin{abstract}
Abstrak
Di era revolusi industri 4.0 saat ini, kebutuhan akan hal efisiensi waktu, tenaga kerja, dan biaya merupakan kebutuhan pokok bagi kehidupan manusia, khususnya yang menyangkut sumber energi listrik. Suplai energi listrik komersial sampai saat ini masih mempergunakan kabel listrik untuk menghantarkan listrik ke beban. Salah satu cara pengiriman daya yang terus dikembangkan oleh peneliti saat ini adalah pengembangan sistem daya listrik nirkabel, yang memiliki kelebihan dalam pemanfaatannya dibandingkan dengan kabel. Kenyamanan peralatan listrik tanpa kabel yang dirasakan oleh pengguna dan berkurangnya sampah listrik yang ditimbulkan, merupakan kelebihan sistem transfer daya nirkabel. Pada penelitian ini akan dikaji mengenai teknik atau metode sistem transfer daya nirkabel medan dekat (near field), yaitu metode kopling induktif, metode kopling resonansi magnetik dan metode kopling kapasitif. Hasil penelitian ini mengusulkan pemodelan transfer daya nirkabel secara optimal agar hasil dan kualitasnya lebih baik, dengan memperhatikan jarak antara pengirim dan penerima karena efisiensi kerja transfer daya nirkabel berkurang terhadap jarak. Dan frekuensi sinyal transmisi rendah untuk kopling induktif, sementara frekuensi yang dihasilkan akan tinggi pada kopling resonansi magnetik dan kopling kapasitif.
\end{abstract}

Kata kunci : transfer daya nirkabel, kopling kapasitif, kopling resonansi magnetik, kopling induktif

\section{Pendahuluan}

Energi listrik merupakan salah satu kebutuhan dan sumber daya ekonomi paling penting di masyarakat saat ini. Di masa yang akan datang, permintaan daya listrik akan terus meningkat seiring dengan peningkatan dan perkembangan populasi penduduk, investasi, dan perkembangan teknologi. Kebutuhan energi listrik meningkat pesat diakibatkan oleh bertambahnya penggunaan peralatan elektronik yang menggunakan listrik [1]. Penelitian lain menyebutkan, sumber energi tak terbarukan yang ada sekarang ini jika pemanfaatannya tidak dilakukan secara efektif dan efisien, maka akan mempengaruhi permintaan daya listrik di masa yang akan datang [2]. Ref [3] mengusulkan, pentingnya menemukan sumber daya energi yang secara alamiah tidak akan habis dan dapat berkelanjutan jika 
dikelola dengan baik. Oleh karena itu, penulis ingin menganalisa beberapa konsep dan karakteristik sistem transfer daya nirkabel guna menyumbangkan pemikiran tentang sumber energi listrik terbarukan.

Pemanfaatan dari transfer daya nirkabel cukup beragam, salah satunya adalah di bidang kedokteran. Pada bidang kedokteran atau medis, transfer daya nirkabel digunakan untuk menyuplai daya perangkat-perangkat elektronik implant pada tubuh seorang pasien. Perangkat ini membutuhkan daya terus menerus untuk bekerja dengan baik dalam jangka waktu yang lama. Juga digunakan dalam aplikasi implantasi medis untuk mendeteksi dan mengobati penyakit pada tubuh manusia. Beberapa perangkat elektronik kecil digunakan di luar atau di dalam tubuh. Menurut Ref. [4], transfer daya nirkabel dapat digunakan dalam aplikasi medis sebagai catu daya pada endoskopi kapsul untuk diagnosis gastroenterologis, serta perangkat lain yang ditanamkan di bawah kulit manusia, seperti implan jantung [5]. Ref. [6] melaporkan bahwa frekuensi radio $402 \mathrm{MHz}$ dapat menstimulasi dorsal root ganglion. Perangkat eksternal dapat mengisi daya perangkat implan menggunakan kopling induktif dengan frekuensi $1 \mathrm{MHz}$.

Selain di bidang kedokteran, transfer daya nirkabel juga dapat dimanfaatkan untuk mengisi daya pada perangkat elektronik di rumah maupun di kantor. Pengisian baterai pada perangkat elektronik dapat dilakukan pada ponsel cerdas (smartphone), PC, tablet maupun pemutar radio (radio player) [7]. Penelitian [8] dan [9] menyebutkan bahwa transfer daya nirkabel juga dapat dilakukan untuk kebutuhan di luar ruangan. Misalnya pada pengisian catu daya untuk mobil dan kendaraan listrik yang sedang berjalan. Dan masih banyak lagi aplikasi transfer daya nirkabel untuk berbagai bidang, yang nantinya akan diulas di artikel berikutnya.

\section{Metode Penelitian}

Berdasarkan prinsip mekanis, transfer daya utama dan jarak transfer, metode transfer daya nirkabel dibagi menjadi dua kategori, yaitu kategori medan jauh (far field) dan kategori medan dekat (near field). Metode ini dapat dianggap kategori medan jauh jika panjang gelombang sinyal elektromagnetik lebih kecil dari jarak transfer. Sebaliknya, jika panjang gelombang sinyal elektromagnetik lebih panjang dari jarak transfer, metode ini termasuk kategori medan dekat. Misalnya, ketika frekuensi resonansi relatif rendah (kurang dari $5 \mathrm{MHz}$ ) dan kisaran transfernya pendek (misalnya berjarak $5 \mathrm{~cm}$ ), metode ini disebut transfer daya medan dekat. Ketika frekuensi resonansinya adalah $900 \mathrm{MHz}$ dan kisaran transfer dayanya lebih dari $2 \mathrm{~m}$, metode ini dikategorikan sebagai transfer daya medan jauh [10]. Gelombang mikro, RF, foto listrik, laser, dan akustik dapat diklasifikasikan sebagai metode transfer daya medan jauh, sedangkan kopling induktif, kopling kapasitif dan kopling resonansi magnetik merupakan metode transfer daya medan dekat. Tinjauan artikel kami berfokus pada semua metode transfer daya medan dekat (near field) yaitu, kopling induktif, kopling resonansi magnetik, dan kopling kapasitif.

\section{Kopling Induktif}

Transmisi daya nirkabel metode kopling induktif memanfaatkan fenomena resonansi dari gelombang elektromagnetik, khususnya gelombang radio. Ada fenomena dalam ilmu elektromagnetik yang merupakan fenomena resonansi gelombang elektromagnetik. Dalam ilmu Fisika, resonansi merupakan keadaan di mana objek dapat menyalurkan energinya ke objek lain yang dipisahkan oleh jarak tertentu. Hal inilah yang ingin dimanfaatkan untuk menyalurkan energi listrik menggunakan fenomena resonansi. Menurut Faraday, besarnya induktansi bersama adalah :

$$
M=\frac{N_{2} \phi_{B 2}}{i_{1}}=\frac{N_{1} \phi_{B 1}}{i_{2}}
$$

Ref. [11] melakukan teknik kopling induktif Power Shake untuk interaksi transfer daya perangkat seluler dan menghasilkan transfer daya hingga sekitar 3,1 W. Hal ini memadai untuk mengisi daya pada perangkat ponsel. Menurut referensi tersebut, induktansi bersama terjadi ketika ada dua lilitan yang saling berdekatan seperti ditunjukkan pada Gambar 1 [12]. 


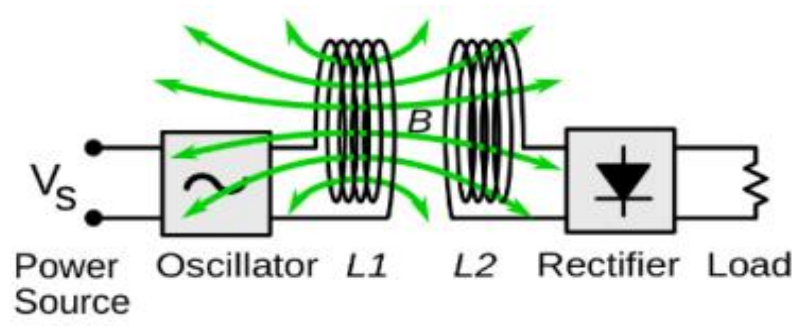

Gambar 1. Diagram blok transfer daya nirkabel kopling induktif Sumber: [12]

Berdasarkan hukum Ampere, koil pemancar (L1) yang dilalui oleh arus bolak-balik (AC) akan mengakibatkan medan magnet berosilasi (B). Kemudian medan magnet melewati koil penerima (L2), di mana ia menginduksi tegangan EMF bolak-balik berdasarkan hukum induksi Faraday. Tegangan tersebut akan menghasilkan arus bolak-balik di sirkuit penerima. Arus bolak-balik yang diinduksi tersebut dapat memindahkan beban secara langsung, dan dapat juga diubah menjadi arus searah (DC) menggunakan sirkuit penyearah, yang kemudian dapat digunakan oleh beban menggunakan tegangan DC.

Pada studi lain [13] mempresentasikan metode transfer daya nirkabel kopling induktif untuk mengisi daya ponsel pada jarak pendek. Mereka merancang power pad yang melibatkan berbagai planar yang tumpang tindih dan koil sebagai pemancar. Perangkat seluler terdiri dari koil planar tunggal sebagai beban atau penerima yang dapat menerima daya hingga 1,2 W. Penelitian ini menyebutkan bahwa efisiensi transfer dari metode kopling induktif berkurang dengan cepat ketika celah udara antara kumparan pengirim dan kumparan penerima diubah, atau aksial misalignment terjadi diantara kumparan.

\section{Kopling Resonansi Magnetik}

Metode kopling resonansi magnetik menggunakan sepasang lilitan yang berpasangan dengan kapasitansi tambahan, membuat pemancar dan penerima memiliki frekuensi resonansi yang sama. Ini memungkinkan transfer daya nirkabel yang efisien pada jarak yang lebih jauh dibandingkan metode yang digabungkan secara kopling induktif. Selama dua lilitan beresonansi, transfer daya antara kedua lilitan tersebut akan terus berlanjut. Ketika dua lilitan beresonansi pada frekuensi yang berbeda, tidak ada daya yang ditransfer antara keduanya. Blok diagram dapat dilihat pada Gambar 2.

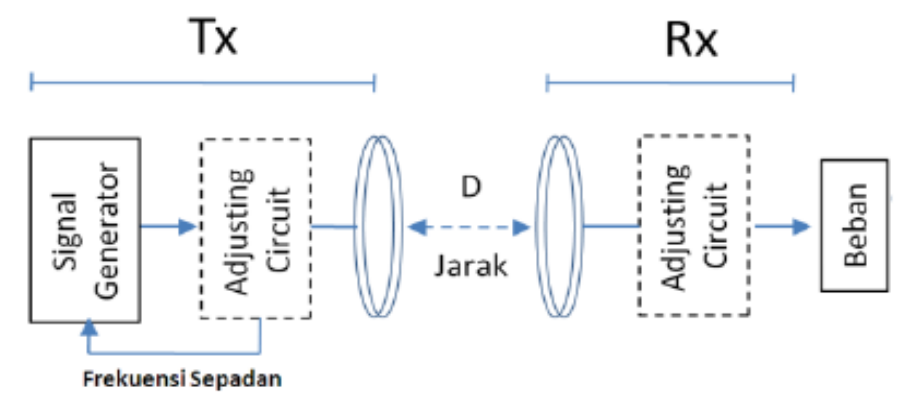

Gambar 2. Kopling resonansi magnetik Sumber: [3]

Penelitian dilakukan oleh [14] menyajikan sirkuit kapasitor untuk metode transfer daya nirkabel. Pemancar bekerja pada frekuensi resonansi 8,3 MHz. Daya yang disampaikan pada koil penerima adalah $28,2 \mathrm{~mW}$. Nilai ini menghasilkan tegangan sebesar 1,68 Volt di koil pemancar. Hasilnya mengungkapkan bahwa ketika koil penerima ditempatkan terpisah $17 \mathrm{~cm}$ dari koil pemancar, tegangan turun dari $3 \mathrm{~V}$ ke $0,57 \mathrm{~V}$. Sementara pada jarak $20 \mathrm{~cm}$, frekuensi yang bekerja pada pengisian dinamis kendaraan listrik adalah sebesar $35 \mathrm{KHz}$ [15].

\section{Kopling Kapasitif}

Serupa dengan kopling induktif, kopling kapasitif dapat digunakan dalam aplikasi daya rendah seperti pada pengisian daya perangkat seluler dan biomedis. Kopling kapasitif biasanya digunakan dalam aplikasi berdaya rendah karena kapasitansi koplingnya kecil. Kopling kapasitif mempunyai kemampuan secara efisien untuk meminimalkan kerugian switching, mengkonsumsi daya rendah, dapat menyediakan stabilitas tegangan pada output, dan memiliki karakteristik sederhana [16]. Ref. [16] juga mengusulkan metode kopling kapasitif yang dibentuk oleh dua pelat persegi panjang konduktif, satu bertindak sebagai pemancar dan yang lainnya bertindak sebagai penerima. Kemudian efek dari beberapa jarak kopling pada 
daya keluaran yang berkisar 0,25-2 mm menghasilkan frekuensi sebesar $1 \mathrm{MHz}$ dan efisiensi transfer daya dalam kisaran 96,3-91\% dapat dicapai. Struktur sederhana rangkaian kopling kapasitif dapat dilihat pada Gambar 3.

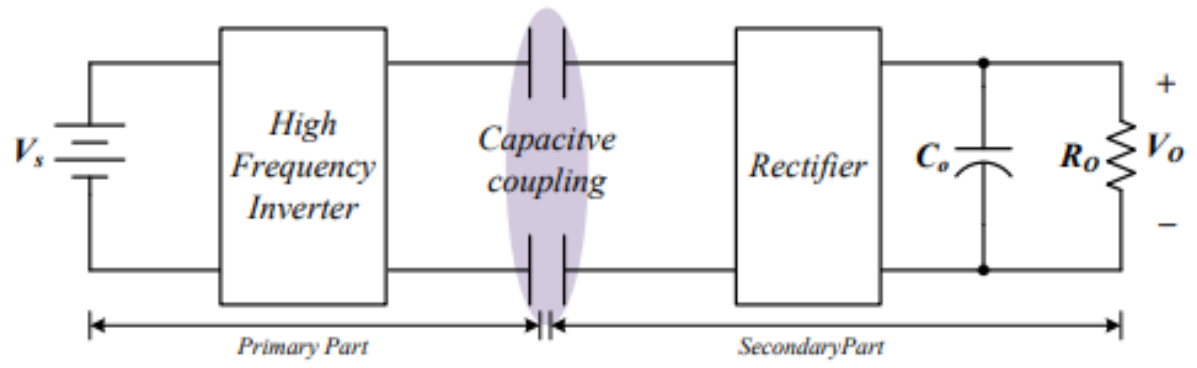

Gambar 3. Struktur sederhana kopling kapasitif Sumber: [17]

Gambar 3 menunjukkan struktur sederhana dari sistem kopling kapasitif. Tegangan arus searah (DC) dikonversi menjadi tegangan arus bolak-balik (AC) frekuensi tinggi yang kemudian disuplai ke dua pelat logam primer oleh inverter frekuensi tinggi. Dua pelat sekunder ditempatkan dekat dengan pelat dan arus perpindahan oleh medan listrik dapat mengalir. Sehingga tegangan keluaran DC dapat diperoleh dengan penyearah. Kapasitansi kopling merupakan faktor penting untuk mentransfer energi [17].

\section{Hasil dan Pembahasan}

Ulasan di atas menyajikan tinjaun singkat tentang kemajuan transfer daya nirkabel dan membandingkan metode transfer daya nirkabel medan dekat (near field) seperti yang terlihat pada Tabel 1. Penerapan teknik ini perlu dikembangkan dan memerlukan penelitian lebih lanjut untuk meningkatkan desain dan jarak transfer daya maksimum selama misalignment sudut atau aksial. Juga untuk mengurangi kerugian sistem ketika frekuensi osilasi tinggi digunakan, dan agar dapat meningkatkan frekuensi dinamis dan skema kontrol daya untuk mengurangi efek gelombang EM sesuai standar internasional.

Tabel 1. Perbandingan transfer daya nirkabel (near field)

\begin{tabular}{llll}
\hline & Kopling Induktif & $\begin{array}{l}\text { Kopling Resonansi } \\
\text { Magnetik }\end{array}$ & Kopling Kapasitif \\
\hline Frekuensi & rendah & tinggi & tinggi \\
Jarak & pendek & sedang & sedang \\
Output & tinggi & rendah & tinggi \\
Metode & koil & resonator & kapasitor \\
Kuat medan & medan magnet & resonansi & medan listrik \\
Efisiensi & tinggi & tinggi & tinggi \\
\hline
\end{tabular}

Sumber: Pengolahan data, 2019

Dari hasil perbandingan transfer daya nirkabel tersebut di atas, terlihat jarak pada metode kopling induktif merupakan yang paling pendek jika dibandingkan dengan metode kopling resonansi magnetik maupun metode kopling kapasitif. Diameter kumparan sangat berpengaruh terhadap efisiensi transfer daya dari pengirim ke penerima. Ref [18] menyebutkan bahwa jarak transmisi akan menjadi lebih panjang ketika diameter kumparan pada pengirim diperbesar. Ada beberapa bentuk kumparan yang dapat digunakan untuk kopling induktif, di antaranya adalah helix coil, planar spiral coil dan square helix coil seperti Gambar 4 [18].

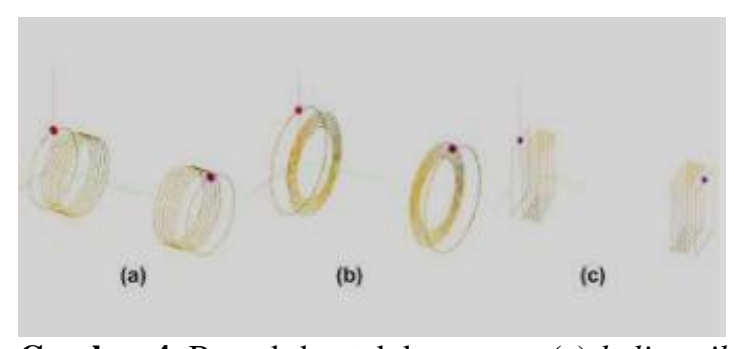

Gambar 4. Bentuk-bentuk kumparan (a) helix coil (b) planar spiral coil (c) square helix coil 
Ref [19] menyebutkan bahwa bentuk kumparan merupakan parameter desain yang penting dan memiliki dampak besar pada efisiensi transfer daya, lebar pita (bandwidth), dan jarak transfer daya maksimumnya. Di sisi lain, metode kopling induktif dapat mentransfer daya dengan efisiensi tinggi. Bahkan baru-baru ini, sebuah konsorsium industri telah dibentuk untuk membakukan teknologi ini untuk pengisian daya pada perangkat seluler. Tetapi, pita frekuensi rendah biasanya hanya mentransfer daya dalam jarak yang sangat pendek, misalnya hanya dalam jarak beberapa $\mathrm{cm}$ saja. Selain itu, pada kopling induktif dapat digunakan untuk aplikasi dengan efisiensi tinggi dan celah udara pendek, misalnya ponsel. Sedangkan untuk aplikasi menengah, kopling induktif dapat digunakan untuk aplikasi pengisian daya pada Wireless Sensor Network (WSN) atau Unmanned Aerial Vehicle (UAV), dengan jarak transfer yang sesuai.

Pada metode kopling resonansi magnetik, dilakukan metode dengan cara menyamakan frekuensi pada sisi pengirim (transmitter) dan pada sisi penerima (receiver) untuk mengetahui besar impedansi yang dihasilkan, dan hal ini akan mempengaruhi transfer dayanya. Oleh karena, perlu dilakukan matching impedance. Penelitian [20] mengusulkan metode penyesuaian impedansi dengan cara menyesuaikan jarak atau sudut relative antara kumparan yang berdekatan, meskipun di dalam prakteknya metode seperti ini sulit diwujudkan karena membutuhkan sistem kontrol yang rumit serta aktuator yang akurat.

Jarak sangat mempengaruhi tegangan dan daya pancar. Ref [21] menyebutkan bahwa tegangan dan daya pancar yang dihasilkan akan semakin kecil apabila jarak semakin jauh. Dan sebaliknya, apabila jarak semakin dekat, maka tegangan yang dihasilkan dan daya pancarnya semakin besar.

\section{Kesimpulan}

Studi ini memperkenalkan ulasan metode transfer daya nirkabel medan dekat secara akademis. Juga menyajikan tinjauan singkat tentang kemajuan transfer daya nirkabel di masa yang akan datang, meskipun masih banyak yang harus dikembangkan terkait efisiensi kerja, output atau daya yang dihasilkan, dan jarak jangkauannya. Berdasarkan tabel yang telah dihasilkan, efisiensi kerja transfer daya nirkabel berkurang terhadap jarak. Artinya, transfer daya akan menurun seiring semakin jauh jarak antara pengirim dan penerima serta efisiensinya pun berkurang. Frekuensi sinyal transmisi akan rendah untuk metode kopling induktif, sementara frekuensi yang dihasilkan akan tinggi pada kopling resonansi magnetik dan kopling kapasitif. Maka transfer daya nirkabel dapat difungsikan peruntukannya sesuai spesifikasinya.

\section{Referensi}

[1] Arif Febriansyah Juwito, Sasongko Pramono, T. Haryono, "Optimalisasi Energi Terbarukan pada Pembangkit Tenaga Listrik dalam Menghadapi Desa Mandiri Energi di Margajaya," Jurnal Ilmiah Semesta Teknika, Vol. 15, No. 1, 22-34, 2012.

[2] I. Dinata, W. Sunanda, "Implementasi Wireless Monitoring Energi Listrik Berbasis Web Database," Jurnal Nasional Teknik Elektro - jnte.ft.unand.ac.id Vol: 4, No. 1, 2015.

[3] R. Hidayat, "Sumber Daya Wireless Untuk Menghasilkan Energi Listrik Terbarukan," Jurnal SINERGI, Vol. 20, No. 2, 2016.

[4] Kumagai, T.; Saito, K.; Takahashi, M.; Ito, K, "Design of receiving antenna for microwave power transmission to capsular endoscope." In Proceedings of the International Microwave Workshop Series on Innovative Wireless Power Transmission: Technologies, Systems, and Applications (IMWS), Kyoto, Japan, 12-13 May, 2011.

[5] Kim, S., Ho, J.S., Chen, L.Y., Poon, A.S, "Wireless power transfer to a cardiac implant", Appl, Phys, Lett, 2012.

[6] Chiu, H.-W., Lin, M.-L.; Lin, C.-W., Ho, I.-H.; Lin,W.-T., Fang, P.-H., Li, Y.-C.;Wen, Y.-R. Lu, S.-S.,"Pain control on demand based on pulsed radio-frequency stimulation of the dorsal root ganglion using a batteryless implantable cmos soc," IEEE Trans, Biomed, Circuits Syst, 2010.

[7] Oodachi, N., Kudo, H., Ogawa, K., Shoki, H., Obayashi, S., Morooka, T. "Efficiency improvement of wireless power transfer via magnetic resonance using the third coil" ISAP, 2010.

[8] Imura, T., Uchida, T., Hori, Y. "Flexibility of contactless power transfer using magnetic resonance coupling to air gap and misalignment for ev. World Electr. Veh." 2009, 3, 24-34.

[9] Hanazawa, M., Ohira, T. "Power transfer for a running automobile. In Proceedings of the International Microwave Workshop Series on Innovative Wireless Power Transmission: Technologies, Systems, and Applications" (IMWS), Kyoto, Japan, 12-13 May 2011; pp. 77-80

[10] Sun, T., Xie, X., Wang, Z., "Wireless Power Transfer for Medical Microsystems," Springer: New York, NY, USA, 2013. 
[11] Worgan, P, Knibbe, J, Fraser, M., Martinez Plasencia, D. Powershake, "Power transfer interactions for mobile devices. In Proceedings of the CHI Conference on Human Factors in Computing Systems," Santa Clara, CA, USA, 2016.

[12] Supriyadi, Edi Rakhman, Suyanto, Arif Rahman, \& Noor Cholis Basjaruddin, "Transfer Daya Nirkabel dengan Kopling Induksi”, Seminar Nasional Teknoka, Vol 2, 2017

[13] Waffenschmidt, E, Staring, T, "Limitation of inductive power transfer for consumer applications," Proceedings of the 13th European Conference on Power Electronics and Applications EPE, 2009.

[14] Cannon, B.L, Hoburg, J.F, Stancil, D.D, Goldstein, S.C, "Magnetic resonant coupling as a potential means for wireless power transfer to multiple small receivers," IEEE Trans, Power Electron, 2009.

[15] Chen,W, Liu, C, Lee, C.H. Shan, Z, "Cost-effectiveness comparison of coupler designs of wireless power transfer for electric vehicle dynamic charging," Energies, 2016.

[16] Hwang, S.-H, Kang, C.G, Son, Y.-H, Jang, B.-J, "Software-based wireless power transfer platform for various power control experiments,' Energies, 2015.

[17] Kang Hyun Yi, "High Frequency Capacitive Coupling Wireless Power Transfer using glass dielectric layers", IEEE Wireless Power Transfer Conference (WPTC), 2016

[18] Suroso, Hari Prasetijo, Daru Tri Nugroho, Marlin Ibnu Qosim , "Performance of Analysis System Prototype Wireless Power Delivery of Magnetic Resonance Using Half Inverter Bridge and Helix Coil", Dinamika Rekayasa, Vol 14 No.2 hal 77-78, 2018

[19] Xinzhi Shi, Chang Qi, Meiling Qu, Shuangli Ye, Gaofeng Wang, Lingling Sun, Zhiping Yu, "Effects of Coil Shapes on Wireless Power Transfer Via Magnetic Resonance Coupling", Journal of Electromagnetic Waves and Applications, vol. 28, no. 11, pp. 1316-1324, 2014

[20] Duong, T.P., Lee, J.-W. "Experimental results of high-efficiency resonant coupling wireless power transfer using a variable coupling method." IEEE Microw. Wirel. Compon. Lett. 2011, 21, 442-444

[21] Ramdhani, Waluyo, Saodah, "Perancangan dan Realisasi Listrik Wireless Menggunakan Resonant Coupling Magnetic", Jurnal Reka Elkomika, Januari 2013 